\title{
Advice for Student Authors How to Organize Your Research Article
}

\author{
Editorial Staff \\ American Journal of Undergraduate Research \\ University of Northern lowa \\ Cedar Falls, lowa 50614-0150 USA
}

\begin{abstract}
General information about article organization is presented. Questions about equation placement, chart or graph usage, figure placement, and bibliographic style are answered. Information about how a paper is reviewed is discussed, and steps for submitting a research paper are outlined.
\end{abstract}

\section{ORGANIZATION}

You may organize your research article as you and your research supervisor agree is best, but some form of Introduction is encouraged. Students who are not familiar with your topic will need some background. Make sure you provide some introductory or general references for your research topic. The research articles in this issue provide a spectrum of ways in which topics can be organized.

\section{EQUATIONS, FIGURES, AND GRAPHS}

Equations, figures and graphs will be printed can appear within a single column (of the two-column format) or can be placed across the entire page. Equations are not normally numbered unless they are referenced later in the article. Make sure that the labels on your figures and graphs will be large enough to be read when reduced during publication. See the current issue for examples.

\section{BIBLIOGRAPHIC STYLES}

You can use whichever bibliographic style your supervisor suggests. The AJUR house style will be applied during publication.

\section{STEPS FOR SUBMITTING A RESEARCH PAPER TO AJUR}

Your research is completed and your research supervisor has approved your written report. What do you need to do to get your report reviewed for publication in AJUR? Follow these steps:
1. Prepare a single-spaced, single-column draft, preferably in WORD. Place figures and graphs in your draft in the locations where they should go.

2. Select an editor (see pp. ii and iii) in an area appropriate to your research. Send him or her a copy of your draft article as an e-mail attachment. Make sure that your e-mail tells the editor the following: your name and college; your research supervisor's name and e-mail address; a mailing address where you will be in a month's time (college or home). Your research supervisor should send the editor a separate e-mail giving permission for your work to be published in AJUR, if accepted.

\section{TIMELINE AFTER YOUR PAPER REACHES AN EDITOR}

The editor will reply by e-mail to you and your research supervisor telling you that your draft article has been received. The editor will then send your draft to at least two referees (college professors or research scientists). They will provide feedback to the editor on your draft in about two or three weeks. The editor will copy the referees' comments to you (without including the names or addresses of the reviewers). If they recommend that you rewrite your draft or rework a part of your project, the editor will likely ask you to comply and may make some recommendations to help you do this. If the referees recommend that your draft be published as is, the editor will forward it to the Editor in Cedar Falls, who will contact you and your supervisor by e-mail with publication details. Good luck! 


\section{PUBLICATION SCHEDULE}

The American Journal of Undergraduate Research will be published four times each year in March, June, September, and December. Volumes begin with June and end with the March issue. The publication schedule for volumes $1 \& 2$ is as follows:

Volume 1

$\begin{array}{ll}\text { Number 1 } & \text { June 2002 } \\ \text { Number 2 } & \text { September 2002 } \\ \text { Number 3 } & \text { December 2002 } \\ \text { Number 4 } & \text { March 2003 }\end{array}$

Volume 2

$\begin{array}{ll}\text { Number 1 } & \text { June 2003 } \\ \text { Number 2 } & \text { September 2003 } \\ \text { Number 3 } & \text { December 2003 } \\ \text { Number 4 } & \text { March 2004 }\end{array}$

Issues will appear in print in the month indicated (e.g., Vol. 2, No. 2 will be in circulation during September 2003).

\section{SUBSCRIPTION INFORMATION}

(1 June 2003 - 31 May 2004)

Within the US, Mexico, or Canada, Individual \$20.00/per volume year Institution \$40.00/per volume year

All other countries,
Individual
$\$ 28.00$ (by surface mail), $\$ 40.00$ (air freight)
Institution

$$
\$ 48.00 \text { (by surface mail), }
$$$$
\$ 80.00 \text { (air freight) }
$$

Single issues: $\$ 5.00 /$ copy plus postage (free within the US, Mexico or Canada; elsewhere, $\$ 2.00$ by surface or $\$ 10.00$ by air freight).

Cheques should be drawn in US\$ and made payable to: AJUR. Institutions may request an invoice.

SUBSCRIPTIONS: Send payment or an invoice request with a name and address (or an institutional address) to:

American Journal of Undergraduate

Research: Attn: Subscriptions

Physics Bldg., Room 205

University of Northern lowa

Cedar Falls, lowa 50614-0150 USA

\section{INFORMATION FOR ADVERTISERS}

AJUR welcomes advertising from academic institutions and from companies in the business of supplying scientific equipment or services to colleges and universities.

Costs per issue per page (or fraction thereof) are as follows (dimensions are width by height):

Full page ( 6 by 9 inches): $\quad \$ 1000.00$

Half page ( 6 by 4.35 inches): $\quad \$ 500.00$

Quarter page

$$
\begin{array}{ll}
6 \text { by } 2.1 \text { inches } & \$ 250.00 \\
2.9 \text { by } 4.25 \text { inches } & \$ 250.00
\end{array}
$$
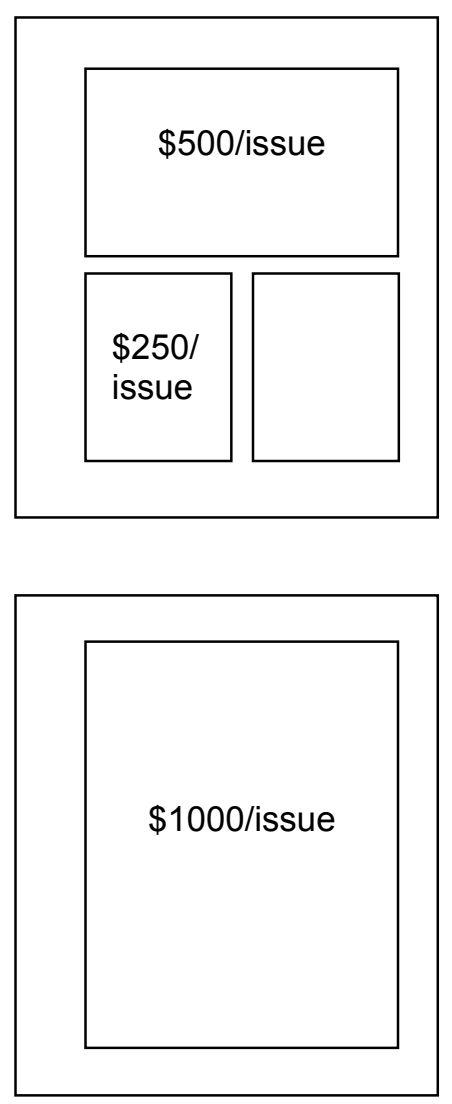

Placement of advertising copy will be upon joint agreement between the advertiser and AJUR. Discounts for pre-arranged multiissue advertising placements are possible. Discounts for not-for-profit entities are also possible.

Interested parties should contact Dr. Cliff Chancey (tel. 319-273-2425 or e-mail c.chancey@uni.edu). 